\title{
High magnitude of under nutrition among HIV infected adults who have not started ART in Tanzania-a call to include nutrition care and treatment in the test and treat model
}

Bruno F. Sunguya ${ }^{1 *} \mathbb{B}$, Nzovu K. Ulenga ${ }^{2}$, Hellen Siril ${ }^{2}$, Sarah Puryear ${ }^{4}$, Eric Aris², Expeditho Mtisi ${ }^{3}$, Edith Tarimo ${ }^{1}$, David P. Urassa ${ }^{1}$, Wafaie Fawzi ${ }^{5}$ and Ferdnand Mugusi ${ }^{1}$

\begin{abstract}
Background: Undernutrition among people living with HIV (PLWHIV) can be ameliorated if nutrition specific and sensitive interventions are integrated into their HIV care and treatment centers (CTC). Integrated care is lacking despite expansion of antiretroviral therapy (ART) coverage, representing a substantial missed opportunity. This research aims to examine nutritional status and associated risk factors among HIV-positive adults prior to ART initiation in Tanzania in order to characterize existing gaps and inform early integration of nutrition care into CTC.

Methods: We analyzed data from 3993 pre-ART adults living with HIV enrolled in CTCs within the Trial of Vitamin (TOV3) and progression of HIV/AIDS study in Dar es salaam, Tanzania. The primary outcome for this analysis was undernutrition, measured as body mass index (BMI) below $18.5 \mathrm{~kg} / \mathrm{m}^{2}$. We conducted descriptive analyses of baseline characteristics and utilized multiple logistic regression to determine independent factors associated with pre-ART undernutrition.

Results: Undernutrition was prevalent in about $27.7 \%$ of pre-ART adults, with a significantly higher magnitude among males compared to females (30\% vs. $26.6 \%, p<0.025)$. Severe undernutrition (BMl $<16.0 \mathrm{~kg} / \mathrm{m}^{2}$ ) was prevalent in one in four persons, with a trend toward higher magnitudes among females ( $26.2 \%$ vs. $21.1 \% p=0.123)$. Undernutrition was also more prevalent among younger adults $(p<0.001)$, those with lower wealth quintiles $(p=0.003)$, and those with advanced HIV clinical stage $(p<0.001)$. Pre-ART adults presented with poor feeding practices, hallmarked by low dietary diversity scores and infrequent consumption of proteins, vegetables, and fruits. After adjusting for confounders and important co-variates, pre-ART undernutrition was associated with younger age, low wealth indices, advanced clinical stage, and low dietary diversity.

Conclusions: One in every four pre-ART PLWHIV presented with undernutrition in Dar es salaam, Tanzania. Risk factors for undernourishment included younger age, lower household income, advanced HIV clinical stage, and lower dietary diversity score. Knowledge of the prevalence and prevailing risk factors for undernutrition among pre-ART PLWHIV should guide targeted, early integration of nutrition interventions into routine HIV care and treatment in high-prevalence, lowincome settings such as Tanzania.
\end{abstract}

Keywords: Undernutrition, Antiretroviral therapy, Nutrition care, And integrated care

\footnotetext{
* Correspondence: sunguya@gmail.com

${ }^{1}$ Afya Bora Consortium, School of Public Health and Social Sciences,

Muhimbili University of Health and Allied Sciences, 9, United Nations Road,

Upanga West, Dar es salaam, Tanzania

Full list of author information is available at the end of the article
} 


\section{Background}

Massive gains have been achieved in the fight against HIV/AIDS owing to the global efforts in rolling out effective interventions [1]. These include treatment with potent antiretroviral drugs, strategies to prevent mother to child transmission, advocacy, and other behavior modification interventions. Such interventions have led to a significant decline in HIV prevalence in the most affected countries in sub Saharan Africa-Tanzania is no exception [2]. For example, the prevalence of HIV among adults aged 15-49 in Tanzania has declined from $7.0 \%$ in 2004 [3] to $5.3 \%$ in 2012 [4], and $4.7 \%$ in 2015. Moreover, the incidence of the disease has also declined to below $1 \%$ of the general population [5].

The decline in HIV prevalence in Tanzania is partially attributable to increased ART coverage. The cumulative number of people on ART in Tanzania increased by $50 \%$ in only 1 year between 2011 to 2012 [4]. By 2015, about $47.6 \%$ of people living with HIV (PLWHIV) were on ART [5]. However, even with such efforts, HIV case fatality rate has remained high. A total of 47,860 people died of disease in 2015 alone [5]. Such poor treatment outcomes have been attributed to poor viral suppression, continued immune suppression, poor nutritional status, opportunistic infections, and non-communicable diseases owing to chronic HIV/AIDS [6]. Tailor-made interventions are therefore needed to address modifiable factors and should be integrated into their routine HIV care and treatment.

Improving nutritional status may be an entry point in addressing many other risk factors among PLWHIV. Evidence has shown that food insecurity results in poor outcomes among PLWHIV [7]. The most commonly demonstrated negative outcomes have been nutritional status, adherence to medication, and psychological wellbeing [8]. In Tanzania, poor feeding practices are widespread and have been associated with undernutrition $[9,10]$. Despite this evidence, nutrition integrated HIV care is lacking in Tanzania, representing a substantial missed opportunity. Beginning in 2016, the country adopted the test and treat strategy for HIV, which will result in more people on ART and longer durations of treatment. For this strategy to attain its desired effects, HIV-positive adults should also be provided with nutrition care and treatment that is integrated into their routine HIV care and treatment.

To design tailor made interventions for adults living with HIV, it is essential to understand the magnitudes and factors associated with undernutrition in Tanzania. Such evidence has not been published. The aim of the current study was therefore, first, to examine magnitudes and severity of undernutrition among adults enrolled for ART services. The second aim was to examine determinants of undernutrition in such population.
Results from this study aimed to inform the HIV/AIDS program on the needs to integrate other important but left out services to improve treatment outcomes among adults attending care and treatment services in Tanzania and countries with similar HIV/AIDS landscape.

\section{Methods \\ Study design}

This cross-sectional study analyzed secondary data of the baseline phase of a randomized double-blind controlled trial on the efficacy of multivitamins on disease progression among HIV-positive adults in Dar es salaam, Tanzania-the TOV3 trial. We used this data to study ART-naïve adults so as to inform of the needs for integrated nutrition care on ART services. The trial aimed at recruiting a total of 4000 randomized into two intervention arms. Data were collected before ART initiation and the participants were followed for 5 years.

\section{Study settings}

Participants were recruited from seven HIV care and treatment clinics (CTCs). At the time of study preparation, Highly Active Antiretroviral Therapy (HAART) was provided under the Tanzania National AIDS Control Program with the support of the President's Emergency Plan for AIDS Relief program and in collaboration with the Harvard School of Public Health, Muhimbili University of Health and Allied Sciences, and the City of Dar es Salaam Regional Office of Health in only seven CTCs. Those CTCs were Infectious Disease Center (IDC), Buguruni, Mwananyamala, Temeke, Mbagala-Rangitatu, Amana, and Sinza CTCs. A CTC is the primary health facility for care and treatment of PLWHIV. Therefore, all CTCs were included as study sites for the TOV3 study. HIV-positive individuals are referred to the CTCs after testing positive in the community, voluntary care and treatment facilities, or any other health facility.

\section{Population and sampling}

The TOV3 study included all confirmed HIV-positive patients who had not started ART and consented to participate. Participant eligibility was determined at the first CTC visit. HIV status was confirmed using two licensed HIV-1 Enzyme-linked immunosorbent assay (ELISA) or two rapid tests, and discordant results were verified via Western Blot. Exclusion criteria included individuals aged below 18 years, and those who would be on transit. For the current paper, we selected adult participants with no missing outcome variables of interest.

\section{Measurements}

The outcome variable of interest in the current study was undernutrition measured through BMI in $\mathrm{kg} / \mathrm{m}^{2}$. BMIs were calculated based on height and weight at 
the first study visit. Undernutrition was defined as BMI of less than $18.5 \mathrm{~kg} / \mathrm{m}^{2}$. Severity of undernutrition was further classified into severe $\left(B M I<16 \mathrm{~kg} / \mathrm{m}^{2}\right)$, moderate (BMI 16 to $<17 \mathrm{~kg} / \mathrm{m}^{2}$ ) and mild (BMI 17 to $\left.<18.5 \mathrm{~kg} / \mathrm{m}^{2}\right)$.

Independent variables included socio-demographic characteristics, feeding practices variables, psychosocial variables, and HIV clinical stage. For demographic characteristics, variables included age (in years), sex, the highest attained level of education, and socio economic status. Dietary characteristics included dietary diversity score. Psychosocial variables included emotional distress score and depression score. We used the World Health Organization's HIV clinical classification to assess the disease progression at the time of recruitment.

Education level was categorized into primary school incomplete, primary school complete, secondary school attended, and advanced education attended. Age in years was divided into quintiles to distribute the age groups evenly. Economic status was assessed using weighted wealth index. It incorporated household assets ownership, housing characteristics, fuel for lighting and cooking, type of toilet, source of water, and feeding characteristics. Dichotomous variables were constructed and factor analysis using principle component analysis (PCA) was used to reduce 31 items to 14 in component one to three. These were the most important components before the hinge of the scree plot. Factor loadings were used as item weights totaled to yield the wealth index for each household. It was then divided into quintiles designating lowest $(-1.56-1.40)$, low (1.41-2.19), middle (2.20-2.71), high (2.72-3.50) and highest (3.514.85) quintiles of the economic status.

Dietary diversity scores were calculated by summing the number of food groups consumed in the day that preceded the enrolment. It was used as a continuous variable and a categorical variable. For the categorical variable, dietary diversity score below three was considered low. Food groups assigned were starch or carbohydrate, any protein, animal protein, plant protein, green vegetables, and fruits. Categorical variables were made for each food groups as none, once, 2-3, and 4 and above times a day.

We measured emotional distress using the Hopkins Symptom Checklist (HSCL), which assigns scores for depression (15 items) and anxiety (10 items). In the current study, the 15-item depression scale had a Cronbach's alpha of 0.9168. The Cronbach's alpha for the 10 -item anxiety scale was 0.8871 . The 25-item HCL checklist had a Cronbach's alpha of 0.9333. Finally, we used the WHO clinical HIV classification to stage the disease progress among the enrollees. Stage one and two are the early stages whereas three and four signify advanced disease.

\section{Data analysis}

Descriptive and regression analyses were used. Chisquare test was used to compare the characteristics of participants by gender and nutritional status for categorical variables. T-test was used for continuous variables. We conducted bivariate logistic regression to examine the associations between each independent variable and undernutrition. Statistical associations with $p$-values below or equal to 0.2 were entered into a multiple logistic regression model to find factors associated with undernutrition after adjusting for confounders and important covariates. Social support and emotional distress were not entered into the model because of their high correlations with depression score. Statistical significance was set at the $p$ value $<0.05$. Missing variables were excluded as cases during regression analyses when the variables introduced into the modules were being analyzed. Analyses were conducted using Stata version 13.

\section{Ethical consideration}

The current study utilized data from the Trial of Vitamin study (TOV3) that observed all ethical guidelines. The parent study was approved by the Institutional Review Board of the National Medical Research Institute (NIMR), Muhimbili University of Health and Allied Sciences (MUHAS), and the Harvard School of Public Health. Participants were assured of confidentiality and anonymity throughout the process and for all reports and publications generated. A written consent was obtained after the participants were explained about the study and agree to voluntarily participate. Participation was voluntary and there were no implications for care at the CTC upon refusal to participate.

\section{Results}

Data of 3993 HIV-positive adults were available for analyses. Of them, 1268 (31.8) were male. The mean age at enrolment to the TOV3 study was 38.0 years, sd. 8.6.

\section{General characteristics}

Male participants had a higher mean age in years compared to their female counterparts (40.9 vs. 36.7, $p<0.001)$. Table 1 shows participants' characteristics. A higher proportion of male participants had higher weighted wealth index compared to female. For example, only $15.2 \%$ of males were in the lowest wealth quintile compared to $22.1 \%$ of female participants $(P<0.001)$. Highest attained level of education was also different across the gender profiles. There was no difference in the proportion of participants with the primary level of education $(p=0.949)$. However, a higher proportion of male participants had attended any secondary school class compared to females $(51.8 \%$ vs. $40.2 \%, p=0.001)$ 
Table 1 General characteristics of TOV study participants

\begin{tabular}{|c|c|c|c|c|c|c|c|}
\hline \multirow[t]{2}{*}{ Variable } & \multicolumn{2}{|l|}{ Male } & \multicolumn{2}{|c|}{ Female } & \multicolumn{2}{|l|}{ Total } & \multirow[t]{2}{*}{$p$} \\
\hline & $\overline{N(\bar{x})}$ & $\%(\mathrm{SD})$ & $\overline{N(\bar{x})}$ & $\%(\mathrm{SD})$ & $\bar{N}$ & $\%$ & \\
\hline \multicolumn{8}{|c|}{ Socio-demographic characteristics } \\
\hline \multicolumn{8}{|l|}{ Wealth index } \\
\hline Lowest & 151 & 15.2 & 498 & 22.1 & 649 & 20.0 & \multirow[t]{5}{*}{$<0.001$} \\
\hline Low & 177 & 17.82 & 480 & 21.3 & 657 & 20.2 & \\
\hline Middle & 242 & 24.4 & 492 & 21.8 & 734 & 22.6 & \\
\hline High & 215 & 21.7 & 413 & 18.3 & 628 & 19.4 & \\
\hline Highest & 208 & 20.9 & 370 & 16.5 & 578 & 17.8 & \\
\hline \multicolumn{8}{|l|}{ Primary school } \\
\hline Completed & 743 & 86.5 & 1659 & 86.4 & 2402 & 86.4 & \multirow[t]{2}{*}{0.949} \\
\hline Not completed & 116 & 13.5 & 261 & 13.6 & 377 & 13.6 & \\
\hline \multicolumn{8}{|c|}{ Secondary education } \\
\hline Any class & 170 & 51.8 & 254 & 40.2 & 424 & 44.2 & \multirow[t]{2}{*}{0.001} \\
\hline None & 158 & 48.2 & 378 & 59.8 & 536 & 55.8 & \\
\hline \multicolumn{8}{|l|}{ Advanced schooling } \\
\hline Any level & 73 & 29.6 & 89 & 17.7 & 162 & 21.6 & \multirow[t]{2}{*}{$<0.001$} \\
\hline None & 174 & 70.4 & 415 & 82.3 & 589 & 78.4 & \\
\hline \multicolumn{8}{|l|}{ Nutritional status (BMI) } \\
\hline \multicolumn{8}{|l|}{ Nutritional status } \\
\hline Underweight & 380 & 30.0 & 724 & 26.6 & 1104 & 27.7 & \multirow[t]{3}{*}{$<0.001$} \\
\hline Normal & 769 & 60.7 & 1506 & 55.3 & 2275 & 57.0 & \\
\hline Overweight & 119 & 9.3 & 495 & 18.1 & 614 & 15.3 & \\
\hline \multicolumn{8}{|c|}{ Severity of undernutrition } \\
\hline Severe & 80 & 21.1 & 190 & 26.2 & 270 & 24.4 & \multirow[t]{3}{*}{0.123} \\
\hline Moderate & 81 & 21.3 & 157 & 21.7 & 238 & 21.6 & \\
\hline Mild & 219 & 57.6 & 377 & 52.1 & 596 & 54.0 & \\
\hline \multicolumn{8}{|l|}{ Feeding practices } \\
\hline \multicolumn{8}{|l|}{ Dietary diversity } \\
\hline Mean & $(2.94)$ & $(0.05)$ & $(2.94)$ & $(0.03)$ & & & 0.424 \\
\hline DDS $<3$ & 459 & 46.2 & 985 & 46.1 & 1444 & 46.1 & \multirow[t]{2}{*}{0.945} \\
\hline DDS $>=3$ & 534 & 53.8 & 1152 & 53.9 & 1686 & 53.9 & \\
\hline \multicolumn{8}{|l|}{ Any starchy } \\
\hline None & 93 & 9.5 & 182 & 8.5 & 275 & 8.8 & \\
\hline Once & 833 & 83.9 & 1782 & 83.4 & 2615 & 83.6 & 0.294 \\
\hline $2-3$ & 56 & 5.6 & 155 & 7.2 & 211 & 6.7 & \\
\hline 4 and above & 11 & 1.0 & 18 & 0.9 & 29 & 0.9 & \\
\hline Any protein & & & & & & & \\
\hline None & 299 & 30.1 & 677 & 31.7 & 976 & 31.2 & \\
\hline Once & 647 & 65.2 & 1355 & 63.4 & 2002 & 64.0 & 0.367 \\
\hline $2-3$ & 35 & 3.5 & 89 & 4.1 & 124 & 3.9 & \\
\hline 4 and above & 12 & 1.2 & 16 & 0.8 & 28 & 0.9 & \\
\hline Any Animal prote & & & & & & & \\
\hline None & 313 & 31.5 & 711 & 33.3 & 1024 & 32.7 & \\
\hline
\end{tabular}

Table 1 General characteristics of TOV study participants (Continued)

\begin{tabular}{llllllll}
\hline Once & 634 & 63.9 & 1332 & 62.3 & 1966 & 62.8 & 0.180 \\
2-3 & 34 & 3.4 & 82 & 3.8 & 116 & 3.7 & \\
4 and above & 12 & 1.2 & 12 & 0.6 & 24 & 0.8 & \\
Any other protein & & & & & & & \\
None & 870 & 87.6 & 1884 & 88.2 & 2754 & 88.0 & \\
Once & 119 & 12.0 & 228 & 10.7 & 347 & 11.1 & 0.144 \\
2-3 & 3 & 0.3 & 20 & 0.9 & 23 & 0.7 & \\
4 and above & 1 & 0.1 & 5 & 0.2 & 6 & 0.2 & \\
Any green vegetables & & & & & & \\
None & 605 & 60.9 & 1265 & 59.2 & 1870 & 59.8 & \\
Once & 350 & 35.3 & 778 & 36.4 & 1128 & 36.0 & 0.673 \\
2-3 & 31 & 3.1 & 81 & 3.8 & 112 & 3.6 & \\
4 and above & 7 & 0.7 & 13 & 0.6 & 20 & 0.6 & \\
Any fruits & & & & & & & \\
None & 456 & 47.9 & 999 & 46.8 & 1455 & 46.5 & \\
Once & 470 & 47.3 & 979 & 45.8 & 1449 & 46.3 & 0.348 \\
2-3 and above & 16 & 1.6 & 24 & 1.1 & 40 & 1.3 & \\
\hline
\end{tabular}

and a similar trend was found for advanced schooling (29.6\% vs. $17.7 \%, p<0.001)$.

A total of 1104 (27.7\%) had a BMI score below $18.5 \mathrm{~kg} / \mathrm{m}^{2}$. A higher proportion of them were male compared to female participants $(30.0 \%$ vs. $26.6 \%$, $p<0.001$. Of those with undernutrition, $24.4 \%$ were severe while $21.6 \%$ were moderate and $54.0 \%$ were mild.

The mean dietary diversity score was 2.94 for both sexes. About $46.1 \%$ of all patients consumed less than 3 different types of foods in the day that preceded the interview. As high as $91.2 \%$ of recruited clients consumed starchy foods at least once in the previous day, while only $68 \%$ consumed any type of food with protein at least once during the same period. Animal sources of protein were consumed by about $67 \%$ of those interviewed; only $12 \%$ reported consuming plant related protein-contained foods. About $60 \%$ did not consume any green vegetables and $46.5 \%$ did not consume any type of fruit.

Descriptive characteristics according to nutritional status Table 2 displays the results of descriptive analyses stratified by undernutrition. Younger age was associated with undernutrition. Mean age among individuals with undernutrition was lower compared to those with normal or higher BMI (37.14 sd. 8.59 vs. 38.61 sd. 8.61, $p<0.001$ ). The trend of undernutrition was such that, young ages had higher magnitudes of undernutrition compared to higher age groups, $p=0.003$. Women had a lower 
Table 2 Descriptive analyses, BMI as outcome variable

\begin{tabular}{|c|c|c|c|c|c|c|c|}
\hline \multirow[t]{2}{*}{ Variable } & \multicolumn{2}{|c|}{$\mathrm{BMI}<18.5$} & \multicolumn{2}{|c|}{$\mathrm{BMI}>=18.5$} & \multicolumn{2}{|l|}{ Total } & \multirow[t]{2}{*}{$p$} \\
\hline & $N(\bar{x})$ & $\%(S D)$ & $\mathrm{N}(\overline{\mathrm{x}})$ & $\%(S D)$ & $\mathrm{N}$ & $\%$ & \\
\hline Age (mean years) & (37.14) & $(8.59)$ & $(38.32)$ & $(8.61)$ & 3999 & & $<0.001$ \\
\hline \multicolumn{8}{|l|}{ Age (years) } \\
\hline $18.47-30.65$ & 249 & 22.6 & 551 & 19.0 & 800 & 20.0 & \multirow[t]{5}{*}{0.003} \\
\hline $30.66-34.96$ & 234 & 21.2 & 566 & 19.6 & 800 & 20.0 & \\
\hline 34.97-39.07 & 231 & 20.9 & 569 & 19.7 & 800 & 20.0 & \\
\hline $39.08-44.80$ & 204 & 18.5 & 596 & 20.6 & 800 & 20.0 & \\
\hline $44.80-83.35$ & 186 & 16.8 & 613 & 20.1 & 799 & 20.0 & \\
\hline \multicolumn{8}{|l|}{ Sex } \\
\hline Male & 380 & 30.0 & 888 & 70.0 & 1268 & 31.8 & \multirow[t]{2}{*}{0.025} \\
\hline Female & 724 & 26.6 & 2001 & 73.4 & 2725 & 68.2 & \\
\hline \multicolumn{8}{|l|}{ Wealth index } \\
\hline Lowest & 217 & 26.6 & 434 & 17.8 & 651 & 20.0 & \multirow[t]{5}{*}{$<0.001$} \\
\hline Low & 196 & 24.0 & 462 & 19.0 & 658 & 20.2 & \\
\hline Middle & 175 & 21.5 & 560 & 23.0 & 735 & 22.6 & \\
\hline High & 123 & 15.1 & 506 & 20.8 & 629 & 19.4 & \\
\hline Highest & 105 & 12.8 & 473 & 19.4 & 578 & 17.8 & \\
\hline Emotional distress & $(1.29)$ & $(0.43)$ & $(1.25)$ & $(0.39)$ & 3055 & & 0.019 \\
\hline Depression score & $(1.35)$ & $(0.52)$ & $(1.30)$ & $(0.48)$ & & & 0.010 \\
\hline \multicolumn{8}{|l|}{ Depression } \\
\hline Yes & 779 & 70.4 & 1849 & 63.6 & 2628 & 65.5 & \multirow[t]{2}{*}{$<0.001$} \\
\hline No & 327 & 29.6 & 1057 & 36.4 & 1384 & 34.5 & \\
\hline Social support & $(25.37)$ & $(8.00)$ & $(25.07)$ & $(8.39)$ & 3154 & & 0.381 \\
\hline \multicolumn{8}{|l|}{ Alcohol dependency } \\
\hline Yes & 4 & 1.4 & 17 & 2.1 & 21 & 1.9 & \multirow[t]{2}{*}{0.005} \\
\hline No & 290 & 98.6 & 797 & 97.9 & 1091 & 98.1 & \\
\hline \multicolumn{8}{|l|}{ HIV clinical stage } \\
\hline Stage 1 & 12 & 1.2 & 181 & 6.8 & 193 & 5.3 & \multirow[t]{4}{*}{$<0.001$} \\
\hline Stage 2 & 112 & 11.1 & 522 & 19.5 & 634 & 17.2 & \\
\hline Stage 3 & 599 & 59.4 & 1701 & 63.8 & 2300 & 62.6 & \\
\hline Stage 4 & 285 & 28.3 & 264 & 9.9 & 549 & 14.9 & \\
\hline \multicolumn{8}{|l|}{ Dietary diversity } \\
\hline Mean & $(2.90)$ & $(1.56)$ & $(2.97)$ & $(1.61)$ & 3137 & & 0.280 \\
\hline DDS $<3$ & 399 & 48.7 & 1050 & 45.3 & 1449 & 46.2 & \multirow[t]{2}{*}{0.099} \\
\hline DDS $>=3$ & 421 & 51.3 & 1267 & 54.7 & 1688 & 53.8 & \\
\hline
\end{tabular}

magnitude of undernutrition compared to their male counterparts $(30.0 \%$ vs. $26.6 \%, p=0.025)$. As expected, wealth index was associated with undernutrition. The lower weighted wealth index quintiles had higher magnitudes of undernutrition, while as the weighted wealth index increased, the BMI tended to increase, $p<0.001$.

There were significant differences in psychosocial variables among those with low compared to those with normal or higher BMI. For example, mean emotional distress was higher among individuals with undernutrition compared with their counterparts (1.29 sd. 0.43 vs. 1.25 sd. $0.39, p=0.019)$. Mean score in the depression scale was also higher among individuals with undernutrition compared to their counterparts $(1.35 \mathrm{sd} .0 .52$ vs. $1.30 \mathrm{sd}$. $0.48, p=0.010)$. Magnitude of depression was high in this population. For example, about $65.5 \%$ of the enrolled HIV-positive individuals had depression symptoms. A higher proportion was among individuals with undernutrition compared to their counterparts $(70.4 \%$ vs $63.6 \%$, $p<0.001$ ). There was no difference in social support indicators between individuals with or without undernutrition $(p=0.381)$. A total of $4(1.4 \%)$ individuals with alcohol dependency had undernutrition compared to $17(2.1 \%)$ who had normal nutritional status $(p=0.005)$.

HIV clinical stage was also associated with undernutrition. For example, only $1.2 \%$ of individuals with stage 1 were underweight status compared to $59.4 \%$ of those with stage 3 and $28.3 \%$ of those with stage 4 disease. There was no statistically significant difference in dietary diversity among those with undernutrition and their counterparts, however, a lower proportion of those with undernutrition $(89.6 \%)$ had not consumed any of the starchy foods.

\section{Factors associated with undernutrition}

Table 3 shows results of bivariate and multiple logistic regression analyses. At bivariate logistic regression analyses, association between age, sex, wealth index, depression, HIV clinical stage, and emotional distress with nutritional status reached a statistically significant level. Social support and alcohol dependency were not statistically significant in bivariate analyses. The multiple regression analysis model included all statistically significant variables, with the exception of emotional distress, which was excluded due to the high correlation with depression.

Compared to the first age quintile (below 30.6 years), those at the fourth quintile (39.1-44.8 years) were $34 \%$ less likely to have undernutrition $(p=0.005)$ after adjusted for other important confounders and covariates. Moreover, those at fifth age quintile ( $>44.8$ years) were $37 \%$ less likely to have undernutrition compared to their counterparts in the first quintile of age (below 30.6 years), $p=0.002$. Compared to HIV-positive males, females were $13 \%$ less likely to be underweight, but this association did not reach a statistically significant level $(p=0.179)$. Higher wealth index was also associated with better nutritional status. For example, after adjusting for confounders, individuals at middle wealth index were $33 \%$ less likely to have undernutrition compared with those at the lowest weighted wealth index $(p=0.004)$. Similarly, those at higher and highest wealth quintiles were $51 \%$ and $54 \%$ less likely to exhibit undernutrition compared with their counterparts at the lowest wealth index $(p<0.001)$. 
Table 3 Logistic regression analyses on the factors associated with low BMI among the clients enrolled into the study

\begin{tabular}{|c|c|c|c|c|c|c|}
\hline \multirow[t]{2}{*}{ Variable } & \multicolumn{3}{|c|}{ Logistic regression } & \multicolumn{3}{|c|}{ Multiple logistic regression } \\
\hline & $\overline{O R}$ & $95 \% \mathrm{Cl}$ & $P$-value & $\mathrm{AOR}$ & $95 \% \mathrm{Cl}$ & $P$-value \\
\hline \multicolumn{7}{|l|}{ Age (quintiles) } \\
\hline $18.47-30.65$ & 1.00 & & & 1.00 & & \\
\hline $30.66-34.96$ & 0.91 & $0.74-1.13$ & 0.414 & 0.84 & $0.63-1.12$ & 0.241 \\
\hline $34.97-39.07$ & 0.90 & $0.73-1.11$ & 0.326 & 0.84 & $0.63-1.13$ & 0.259 \\
\hline $39.08-44.80$ & 0.76 & $0.61-0.94$ & 0.013 & 0.66 & $0.49-0.88$ & 0.005 \\
\hline $44.80-83.35$ & 0.67 & $0.54-0.84$ & $<0.001$ & 0.63 & $0.46-0.85$ & 0.002 \\
\hline \multicolumn{7}{|l|}{ Sex } \\
\hline Male & 1.00 & & & 1.00 & & \\
\hline Female & 0.85 & $0.73-0.98$ & 0.025 & 0.87 & $0.70-1.07$ & 0.179 \\
\hline \multicolumn{7}{|l|}{ Wealth index } \\
\hline Lowest & 1.00 & & & 1.00 & & \\
\hline Low & 0.85 & $0.67-1.07$ & 0.168 & 0.80 & $0.60-1.06$ & 0.114 \\
\hline Middle & 0.63 & $0.49-0.79$ & $<0.001$ & 0.67 & $0.50-0.88$ & 0.004 \\
\hline High & 0.49 & $0.38-0.63$ & $<0.001$ & 0.49 & $0.37-0.67$ & $<0.001$ \\
\hline Highest & 0.44 & $0.34-0.58$ & $<0.001$ & 0.46 & $0.34-0.63$ & $<0.001$ \\
\hline Depression & 1.23 & $1.05-1.44$ & 0.010 & 1.15 & $0.96-1.38$ & 0.138 \\
\hline \multicolumn{7}{|l|}{ HIV clinical stage } \\
\hline Stage 1 & 1.00 & & & 1.00 & & \\
\hline Stage 2 & 3.24 & $1.74-6.01$ & $<0.001$ & 5.05 & $1.99-12.83$ & 0.001 \\
\hline Stage 3 & 5.31 & $2.94-9.58$ & $<0.001$ & 8.77 & $3.55-21.65$ & $<0.001$ \\
\hline Stage 4 & 16.28 & $8.87-29.90$ & $<0.001$ & 22.90 & $9.08-57.75$ & $<0.001$ \\
\hline \multicolumn{7}{|l|}{ Dietary diversity } \\
\hline DDS $<3$ & 1.00 & & & 1.00 & & \\
\hline DDS $>=3$ & 0.87 & $0.75-1.03$ & 0.099 & 0.79 & $0.66-0.96$ & 0.016 \\
\hline Alcohol dependency & 0.63 & $0.21-1.90$ & 0.414 & & & \\
\hline Emotional distress & 1.26 & $1.04-1.53$ & 0.019 & & & \\
\hline Social support & 1.00 & $0.99-1.01$ & 0.300 & & & \\
\hline
\end{tabular}

The association between depression and undernutrition did not reach a statistical significant level. An increase in the HIV clinical stage was associated with higher magnitudes of undernutrition. For example, patients with HIV clinical stage two were five times more likely to have undernutrition compared to those with clinical stage $1(p=0.001)$. Those with HIV clinical stage 3 were 8.77 times more likely to be underweight compared to those with HIV clinical stage $1(p<0.001)$. Likewise, those at stage 4 were 22.90 times more likely to have undernutrition compared to those with stage 1 of the disease $(p<0.001)$. HIV-positive individuals who had a dietary diversity score of three or above were $21 \%$ less likely to be undernourished $(p=0.016)$.

\section{Discussion}

This study examined magnitudes of undernutrition among pre-ART HIV-positive adults in Dar es salaam,
Tanzania. The study found that, more than one in every four of pre-ART adults had undernutrition measured as BMI below $18.5 \mathrm{~kg} / \mathrm{m}^{2}$. Of them, one in four had a severe form of undernutrition reflected by a BMI below $16.0 \mathrm{~kg} / \mathrm{m}^{2}$. Those with undernutrition were more likely to be of the younger age, low wealth index, advanced HIV clinical stage, and low dietary diversity score.

More than one in four pre-ART HIV-positive adults in Dar es salaam presented with undernutrition. Such unprecedented magnitude of undernutrition is not uncommon in this $[9,11]$ and other areas with similar context [12]. A syndemic theory can help explain such high magnitude of undernutrition in this context. First, the disease itself can exacerbate nutritional debilitation through high-energy expenditure, loss through fever, recurrence of opportunistic infections, including diarrheas that lead to emaciation of lean tissues. Secondly, HIV as a disease can subject the affected people to socio-economic 
disadvantages including food insecurity, poverty, and other challenges associated with undernutrition [13]. People living with HIV are therefore at a higher risk of undernutrition compared to their counterparts in the general population.

Despite such burden, to a large extent, nutrition care and treatment has not been integrated into most HIV care and treatment facilities [14]. Tanzania is no exception. With such magnitudes of undernutrition, HIVpositive individuals are likely to succumb to treatment failure, higher risk of opportunistic infections $[15,16]$, and even mortality [11, 12, 17]. Addressing undernutrition among adults is of paramount importance to attain treatment goals, especially in the new era of test and treat for all HIV-positive individuals.

In this study, undernutrition was associated with a number of modifiable factors. Like in other studies conducted in similar settings among HIV-positive children $[9,10]$, adults were more likely to succumb to undernutrition when they had poor feeding practices such as consuming foods with low dietary diversity. Moreover, only a small proportion consumed protein-rich foods, fruits, or vegetables in their routine meals, similar to other studies [18-20]. Such low diversity diets predispose patients not only to macronutrient undernutrition but also to micronutrient deficits [8]. Poor feeding practices could also be associated with other social demographic disadvantages $[21,22]$. Studies have revealed a link between poor feeding practices with food insecurity, poverty, and other social demographic characteristics [8]. However, in the context of Tanzania, even in areas with high yields of agricultural products, HIV-positive individuals succumb to selective food insecurity and therefore undernutrition [10]. Nutrition specific and sensitive interventions should be integrated within ART services to complement care for these populations [23]. Nutrition specific interventions include improving feeding practices such as frequency, diversity, and quantity. It also includes prevention and treatment of opportunistic infections leading to nutritional challenges such as diarrhea. Nutrition sensitive interventions include improving food insecurity, access to health care, poverty alleviation and education pertinent to food and nutrition.

Like in other contexts, undernutrition among pre-ART individuals was associated with low wealth index [10, 24]. Previous models have established associations between poverty and undernutrition, especially among PLWHIV [8]. For this specific population in Tanzania, such an association calls for establishment of a mechanism to identify those from poor households and to develop an innovative approach to alleviate the effects of poverty. In so doing, we can improve their undernutrition and, in turn, improve their HIV treatment outcomes [10]. Such povertyalleviating interventions include conditional cash transfer
$[25,26]$, small productivity groups, microfinancing of economic activities, and other livelihood programs [27, 28].

Advanced HIV clinical stage was also associated with undernutrition [12]. This should also be taken into consideration when patients are enrolled into care as they are more prone to mortality [12]. Early, integrated and innovative nutrition interventions can improve their outcomes and should be targeted at this vulnerable population.

To achieve better treatment outcomes, the results of this study emphasize the integration of nutrition care and treatment into HIV care and treatment $[29,30]$. This should be done from the moment these individuals are enrolled into care and sustained throughout treatment to attain optimal results [31]. Individuals with depression were more likely to be undernourished in this study although not at the multivariate regression analyses. The high magnitude of depression also emphasizes the needs for integrated services to ameliorate HIVpositive individuals with psychological stress and depressive symptoms to further improve their quality of lives and treatment outcomes. Currently, HIV care and treatment centers do not possess such services in Tanzania.

Results of this study should be interpreted carefully owing to the following limitations. First, this was a secondary analysis of data originally collected for a trial of vitamins. It might therefore have failed to include all confounders that should have been controlled for, especially in regression analyses. Second, results of this study may not be generalizable to the entire country. However, they may be useful in areas with similar context as in Dar es Salaam. Third, we used atypical dietary diversity score. This could have introduced validity challenges of assessment of dietary diversity score of participants.

\section{Conclusion}

The fact that more than one in four pre-HAART HIVpositive adults in Dar es salaam, Tanzania presented with undernutrition in various severity implies nutrition care is needed hand in hand with scaling up of the test and treat strategy. Such unprecedented magnitude of undernutrition was associated with young age, advanced clinical stage, low wealth index, and low dietary diversity. To ameliorate undernutrition and improve treatment outcomes with ART, integration of nutrition and treatment into HIV care and treatment is of paramount importance in Dar es salaam, and areas with similar context.

\footnotetext{
Abbreviations

ABC: Afya Bora Consortium; AIDS: Acquired immunodeficiency syndrome; ART: Antiretroviral therapy; BMI: Body Mass Index; CTC: Care and treatment center; ELISA: Enzyme-linked immunosorbent assay; HAART: Highly active antiretroviral therapy; HIV: Human Immunodeficiency Virus; MUHAS: Muhimbili University of Health and Allied Sciences; NIH: National Institute of Health; NIMR: National Institute of Medical Research; PLWHIV: People living with Human Immuno-deficiency Virus; Sd.: Standard deviation; TOV3: Trial of Vitamin 3
} 


\section{Acknowledgements}

Analysis and manuscript preparation for the current project was made possible by Afya Bora Consortium Fellowship, which is supported by the President's Emergency Plan for AIDS Relief (PEPFAR) and the Office of AIDS Research (OAR) of the U.S. National Institutes of Health through funding to the University of Washington under Cooperative Agreement U91 HA06801 from the US Department of Health and Human Services, Health Resources and Services Administration (HRSA) Global HIV/AIDS Bureau.

\section{Funding}

Authors did not receive any grant for this particular analysis. However, the parent trial (TOV3) was sponsored by the National Institute of Health (NIH). The National Institute of Health had no role in the design, analysis or writing of this article. The first author was an Afya Bora Consortium (ABC) fellow under the Department of Global Health, University of Washington.

\section{Availability of data and materials}

The dataset used during and/or analyzed during the current study is not publicly available because it is still being used for other analyses in a research group. However, the dataset will be available from the corresponding author on reasonable request.

\section{Authors' contributions}

BFS conceived the research questions, analyzed the data, and prepared the first manuscript. SP was involved in drafting the first manuscript. NKU was involved in conception and design of the study, and acquisition of data to be used. HS and EA were involved in drafting the first manuscript. EM was involved in data analysis. DPU and EAMT were involved in drafting the manuscript. WF and FM approved the use of the database, involved in analyses, and revised the manuscript. All authors read and approved the final version of the manuscript.

\section{Ethics approval and consent to participate}

The current study utilized data from the Trial of Vitamin study (TOV3) that observed all ethical guidelines. The parent study was approved by the Institutional Review Board of the National Medical Research Institute (NIMR), Muhimbili University of Health and Allied Sciences (MUHAS), and the Harvard School of Public Health. Participants were assured of confidentiality and anonymity throughout the process and for all reports and publications generated. A written consent was obtained after the participants were explained about the study and agree to voluntarily participate. TOV3 study was registered under ClinicalTrial.org with registration number: NCT00383669.

\section{Consent for publication}

Not applicable.

\section{Competing interests}

The authors declare that they have no competing interests.

\section{Publisher's Note}

Springer Nature remains neutral with regard to jurisdictional claims in published maps and institutional affiliations.

\section{Author details}

${ }^{1}$ Afya Bora Consortium, School of Public Health and Social Sciences, Muhimbili University of Health and Allied Sciences, 9, United Nations Road, Upanga West, Dar es salaam, Tanzania. ${ }^{2}$ Management and Development for Health, Dar es salaam, Tanzania. ${ }^{3}$ African Academy for Public Health, Dar es salaam, Tanzania. ${ }^{4}$ Department of Global Health, University of Washington, Seattle, WA, USA. ${ }^{5}$ Departments of Global Health and Population, Nutrition, and Epidemiology, Harvard T.H. Chan School of Public Health, Boston, MA, USA.

Received: 28 February 2017 Accepted: 6 July 2017

Published online: 03 August 2017

\section{References}

1. UNAIDS. 90-90-90 An ambitious treatment target to help end the AIDS epidemic. Geneva: Joint United Nations Programme on HIV/AIDS (UNAIDS); 2014.

2. UNAIDS. UNAIDS Global Report 2013. Geneva: Joint United Nations Programme on HIV/AIDS (UNAIDS); 2013.
3. TACAIDS, ZAC, NBS, OCGS, ICF. Tanzania HIV/AIDS and Malaria Indicator Survey 2003-2004. Dar es salaam, Tanzania: TACAIDS, ZAC, NBS, OCGS, ICF International. Dar es salaam: Tanzania Commission for AIDS (TACAIDS), Zanzibar AIDS Commission (ZAC), national Bureau of Statistics (NBS), Office of the Chief Government Statistician (OCGS), ICF International; 2004.

4. TACAIDS, ZAC, NBS, OCGS, ICF. Tanzania HIV/AIDS and Malaria Indicator Survey 2011-12. Dar es Salaam, Tanzania. Dar es Salaam: Tanzania Commission for AIDS (TACAIDS), Zanzibar AIDS Commission (ZAC), National Bureau of Statistics (NBS), Office of the Chief Government Statistician (OCGS), and ICF International; 2013.

5. Wang $\mathrm{H}$, Wolock TAC. Estimates of global, regional, and national incidence, prevalence, and mortality of HIV, 1980-2015: the Global Burden of Disease Study 2015. Lancet HIV. 2016;16(S2352-3018):30083-9.

6. Anema A, Vogenthaler N, Frongillo EA, Kadiyala S, Weiser SD. Food insecurity and HIV/AIDS: current knowledge, gaps, and research priorities. Curr HIV/AIDS Rep. 2009;6(4):224-31.

7. Weiser SD, Fernandes KA, Brandson EK, Lima VD, Anema A, Bangsberg DR, Montaner JS, Hogg RS. The association between food insecurity and mortality among HIV-infected individuals on HAART. J Acquir Immune Defic Syndr. 2009;52(3):342-9.

8. Weiser SD, Young SL, Cohen CR, Kushel MB, Tsai AC, Tien PC, Hatcher AM, Frongillo EA, Bangsberg DR. Conceptual framework for understanding the bidirectional links between food insecurity and HIV/AIDS. Am J Clin Nutr. 2011;94(6):1729S-39S

9. Sunguya BF, Poudel KC, Otsuka K, Yasuoka J, Mlunde LB, Urassa DP, Mkopi NP, Jimba M. Undernutrition among HIV-positive children in Dar es salaam, Tanzania: antiretroviral therapy alone is not enough. BMC Public Health. 2011;11:869

10. Sunguya BF, Poudel KC, Mlunde LB, Urassa DP, Yasuoka J, Jimba M. Poor nutrition status and associated feeding practices among HIV-positive children in a food secure region in Tanzania: a call for tailored nutrition training. PLoS One. 2014;9(5):e98308.

11. Woodd SL, Kelly P, Koethe JR, Praygod G, Rehman AM, Chisenga M, Siame J, Heimburger DC, Friis H, Filteau S. Risk factors for mortality among malnourished HIV-infected adults eligible for antiretroviral therapy. BMC Infect Dis. 2016;16(1):562.

12. Tesfamariam K, Baraki N, Kedir H. Pre-ART nutritional status and its association with mortality in adult patients enrolled on ART at fiche Hospital in North Shoa, Oromia region, Ethiopia: a retrospective cohort study. BMC Res Notes. 2016;9(1):512.

13. Himmelgreen DA, Romero-Daza N, Turkon D, Watson S, Okello-Uma I, Sellen D. Addressing the HIV/AIDS-food insecurity syndemic in sub-Saharan Africa. Afr J AIDS Res. 2009;8(4):401-12.

14. Sint T, Lovich R, Hammond W, Kim M, Melillo S, Lu L, Ching P, Marcy J, Rollins $\mathrm{N}$, Koumans $\mathrm{EH}$, et al. Challenges in infant and young child nutrition in the context of HIV. AIDS. 2013;27(Suppl 2):S169-77.

15. Weiser SD, Hatcher A, Frongillo EA, Guzman D, Riley ED, Bangsberg DR, Kushel MB. Food insecurity is associated with greater acute care utilization among HIV-infected homeless and marginally housed individuals in San Francisco. J Gen Intern Med. 2013;28(1):91-8.

16. Ford N, Shubber Z, Meintjes G, Grinsztejn B, Eholie S, Mills EJ, Davies MA, Vitoria M, Penazzato M, Nsanzimana S, et al. Causes of hospital admission among people living with HIV worldwide: a systematic review and metaanalysis. Lancet HIV. 2015;2(10):e438-44.

17. Hussen S, Belachew T, Hussien N. Nutritional status and its effect on treatment outcome among HIV infected clients receiving HAART in Ethiopia: a cohort study. AIDS Res Ther. 2016;13:32.

18. Mpontshane N, Van den Broeck J, Chhagan M, Luabeya KK, Johnson A, Bennish ML. HIV infection is associated with decreased dietary diversity in south African children. J Nutr. 2008;138(9):1705-11.

19. Kadiyala S, Rawat R. Food access and diet quality independently predict nutritional status among people living with HIV in Uganda. Public Health Nutr. 2012:1-7.

20. Rawat R, McCoy S, Kadiyala S. Poor diet quality is associated with low CD4 count and anemia and predicts mortality among antiretroviral therapy-naive HIV-positive adults in Uganda. J Acquir Immune Defic Syndr. 2012;62(2): 246-53.

21. Miller CL, Bangsberg DR, Tuller DM, Senkungu J, Kawuma A, Frongillo EA, Weiser SD. Food insecurity and sexual risk in an HIV endemic community in Uganda. AIDS Behav. 2011;15(7):1512-9.

22. Nagata JM, Magerenge RO, Young SL, Oguta JO, Weiser SD, Cohen CR. Social determinants, lived experiences, and consequences of household 
food insecurity among persons living with HIV/AIDS on the shore of Lake Victoria, Kenya. AIDS Care. 2012;24(6):728-36.

23. Gillespie S, Haddad L, Mannar V, Menon P, Nisbett N, Group MaCNS. The politics of reducing malnutrition: building commitment and accelerating progress. Lancet. 2013;382(9891):552-69.

24. Oldewage-Theron WH, Dicks EG, Napier CE. Poverty, household food insecurity and nutrition: coping strategies in an informal settlement in the Vaal triangle, South Africa. Public Health. 2006;120(9):795-804.

25. Adato M, Bassett L. Social protection to support vulnerable children and families: the potential of cash transfers to protect education, health and nutrition. AIDS Care. 2009:21(Suppl 1):60-75.

26. McCoy SI, Njau PF, Czaicki NL, Kadiyala S, Jewell NP, Dow WH, Padian NS. Rationale and design of a randomized study of short-term food and cash assistance to improve adherence to antiretroviral therapy among food insecure HIV-infected adults in Tanzania. BMC Infect Dis. 2015;15:490.

27. Rawat R, Faust E, Maluccio JA, Kadiyala S. The impact of a food assistance program on nutritional status, disease progression, and food security among people living with HIV in Uganda. J Acquir Immune Defic Syndr. 2014;66(1):e15-22.

28. Yager JE, Kadiyala S, Weiser SD. HIV/AIDS, food supplementation and livelihood programs in Uganda: a way forward? PLoS One. 2011;6(10):e26117.

29. Byron $\mathrm{E}$, Gillespie $\mathrm{S}$, Nangami M. Integrating nutrition security with treatment of people living with HIV: lessons from Kenya. Food Nutr Bull. 2008;29(2):87-97.

30. Lindegren ML, Kennedy CE, Bain-Brickley D, Azman H, Creanga AA, Butler LM, Spaulding AB, Horvath T, Kennedy GE. Integration of HIV/AIDS services with maternal, neonatal and child health, nutrition, and family planning services. Cochrane Database Syst Rev. 2012(9):CD010119.

31. Scarcella P, Buonomo E, Zimba I, Doro Altan AM, Germano P, Palombi L, Marazzi MC. The impact of integrating food supplementation, nutritional education and HAART (highly active antiretroviral therapy) on the nutritional status of patients living with HIV/AIDS in Mozambique: results from the DREAM Programme. Ig Sanita Pubbl. 2011;67(1):41-52.

\section{Submit your next manuscript to BioMed Central and we will help you at every step:}

- We accept pre-submission inquiries

- Our selector tool helps you to find the most relevant journal

- We provide round the clock customer support

- Convenient online submission

- Thorough peer review

- Inclusion in PubMed and all major indexing services

- Maximum visibility for your research

Submit your manuscript at www.biomedcentral.com/submit

) Biomed Central 